\title{
Kinetic studies on the biosorption of phenol by nanoparticles from Spirulina sp. LEB 18
}

\author{
G.L. Dotto ${ }^{a, *}$, J.A.V. Costa ${ }^{b}$, L.A.A. Pinto ${ }^{a}$ \\ ${ }^{a}$ Unit Operation Laboratory, School of Chemistry and Food, Federal University of Rio Grande-FURG, 475 Engenheiro Alfredo Huch street, 96203-900 Rio Grande, RS, Brazil \\ biochemistry Engineering Laboratory, School of Chemistry and Food, Federal University of Rio Grande-FURG, 475 Engenheiro Alfredo Huch street, $96203-900$ Rio Grande, RS, Brazil
}

\section{A R T I C L E I N F O}

\section{Article history:}

Received 20 June 2013

Received in revised form 20 July 2013

Accepted 25 August 2013

\section{Keywords:}

Biosorption

Kinetic models

Nanoparticles

Phenol

\begin{abstract}
A B S T R A C T
A kinetic study on the biosorption of phenol by nanoparticles from Spirulina sp. LEB 18 was carried out. The Spirulina sp. nanoparticles were prepared and characterized. Kinetic curves of phenol biosorption were obtained in batch system, being verified the effects of initial concentration $(50,150,250$ and $450 \mathrm{mg} \mathrm{L}^{-1}$ ) and stirring rate (50, 200 and $\left.400 \mathrm{rpm}\right)$. The models of pseudo-first order, pseudo-second order, Elovich, Bangham, general order and Weber-Morris were used for the kinetic interpretations. Spirulina sp. nanoparticles were stable, monodisperse, spherical with mean diameter of $230 \mathrm{~nm}$. The phenol biosorption was a relatively fast process, being favored at higher values of initial concentration and stirring rate. Pseudo-second order and general order models showed satisfactory fit with the experimental data and the maximum biosorption capacity was around $101 \mathrm{mg} \mathrm{g}^{-1}$. From the WeberMorris analysis, it was found that external mass transfer and intraparticle diffusion occurred during the phenol biosorption on Spirulina sp. nanoparticles. The external mass transfer was faster at higher values of initial concentration and stirring rate, and the intraparticle diffusion was favored at high initial concentrations.
\end{abstract}

(c) 2013 Elsevier Ltd. All rights reserved.

\section{Introduction}

Phenol is a toxic organic pollutant commonly present in industrial effluents from refineries, coking operations, coal processing, manufacture of petrochemicals and others. Its concentration in liquid effluents can reach $6800 \mathrm{mg} \mathrm{L}^{-1}$ [1]. Due its high toxicity and possible accumulation in the environment, phenol is considered a high priority pollutant by Environmental Protection Agency (USEPA) [2]. So, phenol in liquid effluents should be effectively removed before discharge into natural water bodies. For this purpose, treatment technologies, such as, distillation, extraction, membrane pervaporation [1], adsorption [3], catalytic oxidation [4] and advanced oxidation processes [5] are generally employed. Alternatively, biosorption is an emerging technology to treat phenol containing effluents [6,7]. The main advantages of biosorption are: ease of operation, high efficiency, eco-friendly process, minimization of chemical sludge and the use of natural, low-cost and renewable biosorbents [6-9].

In the field of biosorption, some biosorbents have been used to remove phenol from aqueous solutions, for example, Phanerochaete chrysosporium [6], chitosan [7], fungal mycelia [10], marine

\footnotetext{
* Corresponding author. Tel.: +55 5381013033.

E-mail addresses: guilherme_dotto@yahoo.com.br (G.L. Dotto), jorgealbertovc@terra.com.br (J.A.V.Costa), dqmpinto@furg.br (L.A.A. Pinto).
}

seaweeds [11], Funalia trogii [12] and others [3], but, studies about the use of Spirulina sp. are limited. Spirulina is a photosynthetic cyanobacterium [13] and its biomass can be used for biosorption purposes due its characteristics such as: availability in large quantities, it is largely cultivated worldwide, is relatively cheap, renewable and has some functional groups [14-17]. Recent works demonstrated that Spirulina is an alternative biosorbent to remove dyes [18-22] and heavy metals [14,23-25] from aqueous solutions. However, to extend the applicability of Spirulina, becomes interesting verify its behavior in relation to others pollutants like phenol.

The kinetic study is fundamental for the phenol biosorption onto Spirulina [8]. From the kinetic analysis, the solute uptake rate, which determines the residence time required for completion of biosorption reaction, may be established [26]. This study explains how fast the biosorption occurs and also provides information on the factors affecting the process [9]. Furthermore, it is possible to investigate the rate controlling steps [8]. Generally, the biosorption of pollutants by Spirulina is controlled by external mass transfer or/ and intraparticle diffusion $[18,20]$. These steps can be affected by various factors, including phenol concentration and stirring rate $[8,9,18,20,27]$. In this way, it is important the investigation of these effects for the system Spirulina-phenol.

This work aimed to study the biosorption kinetics of phenol onto nanoparticles from Spirulina sp. LEB 18. The nanoparticles from Spirulina sp. LEB 18 were prepared and characterized by 
scanning electron microscopy (SEM), dynamic light scattering (DLS) and Fourier transform infrared spectroscopy (FT-IR). The effects of initial phenol concentration (50-450 $\mathrm{mg} \mathrm{L}^{-1}$ ) and stirring rate (50-400 rpm) on the biosorption kinetics were investigated. The kinetic interpretations were based on the following models: pseudo-first order, pseudo-second order, Elovich, Bangham, general order and Weber-Morris.

\section{Materials and methods}

\section{Cultivation of Spirulina sp. LEB 18}

Spirulina sp. LEB-18 was cultivated according to the procedure presented by Borges et al. [17]. The inoculum was isolated (from the Mangueira Lagoon, southern Brazil) and the cultivation was performed in a medium composed by $80 \%(\mathrm{v} / \mathrm{v})$ of Zarrouk medium and $20 \%(\mathrm{v} / \mathrm{v})$ of an anaerobic digestion effluent [17]. The cultivation was carried out in Raceway-type open bioreactors (working volume of $4 \mathrm{~L}$ ), which were mechanically stirred at $17 \mathrm{rpm}$. The cultures were maintained for 19 days, in a semicontinuous mode with cut-off cellular concentration of $1.0 \mathrm{~g} \mathrm{~L}^{-1}$ and medium renewal rate of $50 \%$. The biomass was recovered by filtration and pressed to recover the biomass with a moisture content of $76 \%$ (wet basis) $[17,28]$. The wet biomass was dried [29], ground (Wiley Mill Standard, No. 03, USA) and sieved until the discrete particle size of $68-75 \mu \mathrm{m}$.

Preparation and characterization of nanoparticles from Spirulina $s p$. LEB 18

The nanoparticles from Spirulina sp. LEB 18 were obtained by a mechanical agitation method as follows $[15,19,20,23]$ : the sieved biomass (concentration of $3.70 \mathrm{~g} \mathrm{~L}^{-1}$ ) was added in distilled water and the $\mathrm{pH}$ was adjusted to 6.0 by buffer disodium phosphate/citric acid solution $\left(0.1 \mathrm{~mol} \mathrm{~L}^{-1}\right)$. After, the suspension was agitated (Dremel, 1100-01, Brazil) at 10,000 rpm for $20 \mathrm{~min}$.

Scanning electron microscopy (SEM) (Jeol, JSM-6060, Japan) was employed to observe the textural characteristics of the nanoparticles from Spirulina sp. LEB 18 [23]. The mean hydrodynamic diameter and polydispersity index of the nanoparticles were obtained by dynamic light scattering (DLS) [30]. The DLS equipment was constituted by a laser (Spectra-physics, 127, USA) coupled to a goniometer (Brookheaven, BI 200M, USA) and a digital correlator (Brookheaven, BI 9000AT USA). Fourier transform infrared spectroscopy (FT-IR) was used to identify the functional groups of the nanoparticles (Prestige 21, the 210045, Japan) [31].

\section{Biosorption kinetic experiments}

The phenol stock solutions ( $1.0 \mathrm{~g} \mathrm{~L}^{-1}$ ) were prepared by diluting solid phenol (94.11 $\mathrm{g} \mathrm{mol}^{-1}$, purity of $99.9 \%$ ) (Vetec, Brazil) in distilled water, being the pH adjusted to 6.0 by buffer disodium phosphate/citric acid solution $\left(0.1 \mathrm{~mol} \mathrm{~L}^{-1}\right)[1,3,12]$. The biosorption kinetic experiments were carried out in a jar-test (Nova ética, $218 \mathrm{MBD}$, Brazil) at $\mathrm{pH}$ 6.0, temperature of $298 \mathrm{~K}$ and nanoparticles dosage of $1.85 \mathrm{~g} \mathrm{~L}^{-1}$ (these conditions were determined by preliminary studies). The effects of initial phenol concentration (50,150, 250 and $\left.450 \mathrm{mg} \mathrm{L}^{-1}\right)$ and stirring rate $(50,200$ and $400 \mathrm{rpm}$ ) were evaluated. Samples were collected in preset time intervals $(0,5,10,15,20,25,30,40,50,60,80,100$ and $120 \mathrm{~min})$, centrifuged at 4,000 for $20 \mathrm{~min}$ (Centribio, 80-2B, Brazil) and the phenol concentration was determined by spectrophotometry (Shimadzu UV-240, Japan) at $270 \mathrm{~nm}$ [12]. All experiments were carried out in triplicate and blanks were performed. The biosorption capacity at time $t\left(q_{t}\right)$, valid when the solute remaining in the liquid filling the pores is negligible, was determined by Eq. (1):

$q_{t}=\frac{C_{0}-C_{t}}{m} V$

where, $C_{0}$ is the initial phenol concentration in liquid phase ( $\left.\mathrm{mg} \mathrm{L}^{-1}\right), C_{t}$ is the phenol concentration in liquid phase at time $t$ ( $\left.\mathrm{mg} \mathrm{L}^{-1}\right), m$ is the amount of nanoparticles $(g)$, and $V$ is the volume of solution $(L)$.

\section{Kinetic models}

Information about the biosorption kinetics of phenol onto nanoparticles from Spirulina sp. LEB 18 were found by fitting the following models: pseudo-first order, pseudo-second order, Elovich, Bangham, general order and Weber-Morris.

The kinetic models of pseudo-first order [32] and pseudosecond order [33] are based in the biosorption capacity. The pseudo-first order model (Eq. (2)) is generally applicable over the initial 20-30 min of the sorption process, while the pseudo-second order model (Eq. (3)) is suitable for the whole range of contact time $[8,9]$.

$$
\begin{aligned}
& q_{t}=q_{1}\left(1-\exp \left(-k_{1} t\right)\right) \\
& q_{t}=\frac{t}{\left(1 / k_{2} q_{2}{ }^{2}\right)+\left(t / q_{2}\right)}
\end{aligned}
$$

being, $k_{1}$ and $k_{2}$ the rate constants of pseudo-first order and pseudo-second order models, respectively, in $\left(\mathrm{min}^{-1}\right)$ and $\left(\mathrm{g} \mathrm{mg}^{-1} \mathrm{~min}^{-1}\right), q_{1}$ and $q_{2}$ are the theoretical values for the biosorption capacity ( $\mathrm{mg} \mathrm{g}^{-1}$ ).

The Elovich equation (Eq. (4)) is one of the most useful models for describing such activated chemical sorption and is suitable for heterogeneous systems [34].

$q_{t}=\frac{1}{a} \ln (1+a b t)$

where, $a$ is the initial velocity due to $d q / d t$ with $q_{t}=0\left(\mathrm{mg} \mathrm{g}^{-1} \mathrm{~min}^{-1}\right)$ and $b$ is the desorption constant of the Elovich model $\left(\mathrm{g} \mathrm{mg}^{-1}\right)$.

From the biosorption kinetic data it is possible to check whether pore diffusion is the only rate-controller step, using the Bangham equation (Eq. (5)) [35]:

$\log \left[\log \left(\frac{C_{0}}{C_{0}-q_{t} m}\right)\right]=\log \left(\frac{k_{0} m}{2.303 V}\right)+\alpha \log (t)$

where, $k_{0}\left(\mathrm{Lg}^{-1}\right)$ and $\alpha$ are Bangham constants.

An alternative to the pseudo-first order and pseudo-second order models is the general order model $[9,22]$. For this model, the biosorption process on the surface of biosorbent is assumed to be rate controlling step [9]. The general order model can be described by Eq. (6) [22]:

$q_{t}=q_{n}-\frac{q_{n}}{\left[k_{n}\left(q_{n}\right)^{n-1} t(n-1)+1\right]^{1 /(n-1)}}$

being, $q_{n}$ the biosorption capacity at the equilibrium ( $\left.\mathrm{mg} \mathrm{g}^{-1}\right), k_{n}$ the rate constant $\left(\mathrm{min}^{-1}\left(\mathrm{~g} \mathrm{mg}^{-1}\right)^{\mathrm{n}-1}\right)$ and $n$ is the biosorption reaction order with regard to the effective concentration of the biosorption sites available on the surface of biosorbent.

The Weber-Morris intraparticle diffusion model [36] is given by Eq. (7):

$q_{t}=k_{d i} t^{1 / 2}+C_{i}$ 
where, $k_{d i}$ is the intraparticle diffusion rate constant $\left(\mathrm{mg} \mathrm{g}^{-1} \mathrm{~min}^{-1 / 2}\right), C$ is the constant in the intraparticle diffusion model $\left(\mathrm{mg} \mathrm{g}^{-1}\right)$, which is proportional to the boundary layer thickness and $i$ is the number of each biosorption stage. This is the most useful model used to identify the mass transfer steps that occur in the biosorption process $[22,26,27]$.

\section{Statistical evaluation of the fitted models}

The kinetic parameters were determined by the fit of the models (Eqs. (2)-(7)) with the experimental data through nonlinear regression using the Quasi-Newton estimation method. The calculations were carried out by the Statistic 7.0 software (Statsoft, USA). The fit quality and the accuracy of the kinetic parameters were measured through determination coefficient $\left(R^{2}\right)$, adjusted determination coefficient $\left(R^{2}{ }_{a d j}\right)$, average relative error (ARE) and sum of squared errors (SSE) [37], as showed in Eqs. (8)-(11):

$$
\begin{aligned}
& R^{2}=\left(\frac{\sum_{n}^{i}\left(q_{i, \exp }-\bar{q}_{i, \exp }\right)^{2}-\sum_{n}^{i}\left(q_{i, \exp }-q_{i, \text { model }}\right)^{2}}{\sum_{n}^{i}\left(q_{i, \exp }-\bar{q}_{i, \exp }\right)^{2}}\right) \\
& R_{a d j}^{2}=1-\left(1-R^{2}\right) \cdot\left(\frac{n-1}{n-p}\right)
\end{aligned}
$$$$
A R E=\frac{100}{n} \sum_{i=1}^{n}\left|\frac{q_{i, \text { model }}-q_{i, \exp }}{q_{i, \exp }}\right|
$$$$
\text { SSE }=\sum_{i=1}^{n}\left(q_{i, \text { model }}-q_{i, \exp }\right)^{2}
$$

where, $q_{i \text {,model }}$ is each value of $q$ predicted by the fitted model, $q_{i, \exp }$ is each value of $q$ measured experimentally, $\bar{q}_{i, \exp }$ is the average of $q$ experimentally measured, $n$ is the number of experimental points, and $p$ is the number of parameters of the fitted model.

In addition, AIC (Akaike information criterion) (Eq. (12)) was used to verify the reliability of the fitted models. The AIC is a methodology for model selection in a situation where more than one model has been fitted to experimental data and the most appropriate model is to be identified. The model for which $A I C$ is a minimum describes the experimental data best [38].

$A I C=n \ln \left(\frac{S S E}{n}\right)+2 p+\frac{2 p(p+1)}{n-p-1}$

\section{Results and discussion}

\section{Characteristics of nanoparticles from Spirulina sp. LEB 18}

Fig. 1 shows the SEM images of (a) Spirulina sp. LEB 18 biomass and (b) nanoparticles from Spirulina sp. LEB 18. The typical multicellular cylindrical trichomes of the Spirulina sp. microalgae $[13,23]$ were observed in Fig. 1(a). From Fig. 1(b) it was found that the nanoparticles from Spirulina sp. LEB 18 were homogeneous with a spherical form. The DLS analysis demonstrated that the nanoparticles from Spirulina sp. LEB 18 were stable, monodisperse (polydispersity index of 0.155 ) with hydrodynamic mean diameter of $230 \mathrm{~nm}$. Based on the vibrational bands and its respective assignments (FT-IR), as presented in Table 1, it can be inferred that the nanoparticles from Spirulina sp. LEB 18 contains the following functional groups in its structure: amines, amides, aldehydes, ketones, hydroxyls, sulfates and phosphates. These groups were

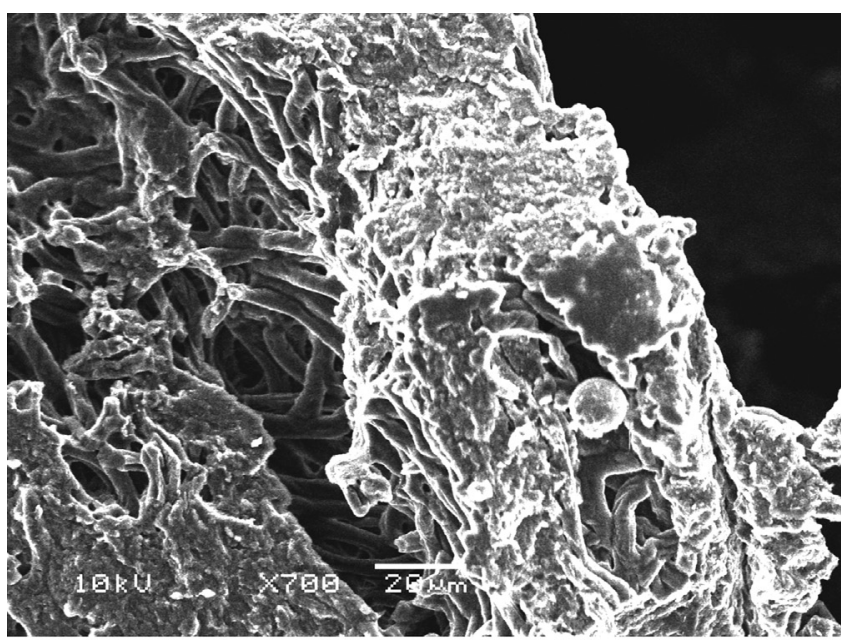

(a)

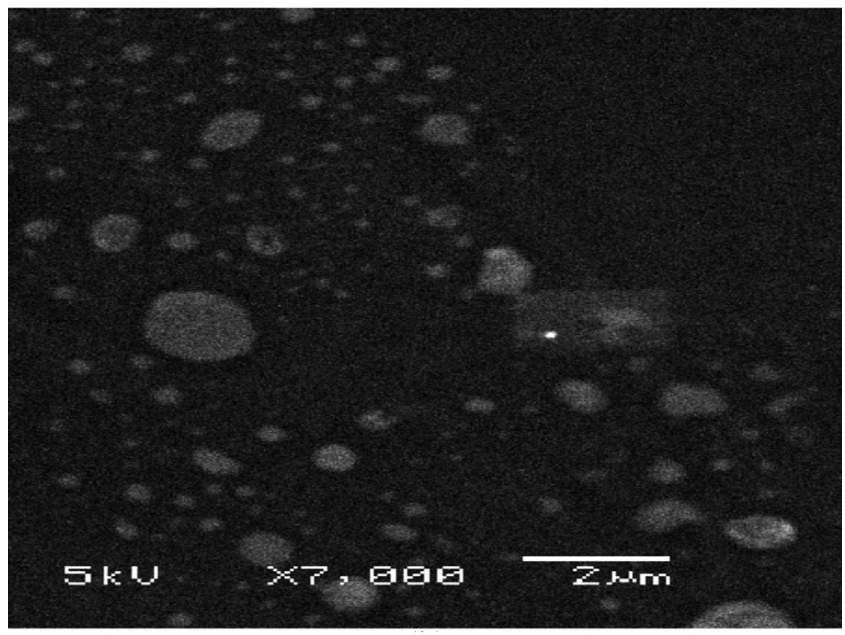

(b)

Fig. 1. SEM images of (a) Spirulina sp. LEB 18 biomass and (b) nanoparticles from Spirulina sp. LEB 18.

also identified in other works which Spirulina was used [14,15]. Based on the literature [18-25], SEM, DLS and FT-IR, it can be affirmed that the nanoparticles from Spirulina sp. LEB 18 has potential characteristics to remove pollutants from aqueous media.

In order to confirm the presence of phenol on the nanoparticles, FT-IR analysis was also realized after the biosorption process. It was found that, after the biosorption, the intensity of aromatic $\mathrm{O}-\mathrm{H}$ stretching was increased $\left(3370 \mathrm{~cm}^{-1}\right)$ and, a new band at $1602 \mathrm{~cm}^{-1}$ appeared. This new band could be assigned to the $\mathrm{C}=\mathrm{C}$ aromatic stretchings. These results indicate the presence of

Table 1

FT-IR bands and respective assignments for the nanoparticles from Spirulina sp. LEB 18.

\begin{tabular}{ll}
\hline Bands $\left(\mathrm{cm}^{-1}\right)$ & Assignment \\
\hline 3370,3275 & O-H and $\mathrm{N}-\mathrm{H}$ stretching \\
2900 & Asymmetric stretching of $\mathrm{CH}_{2}$ \\
1645,1633 & Scissor bending of $\mathrm{NH}_{2}$ \\
1550,1540 & Interaction $\mathrm{N}-\mathrm{H}$ bending with $\mathrm{C}-\mathrm{N}$ stretching \\
1460 & $\mathrm{NH}_{4}^{+}$bending \\
1420 & $\mathrm{C}-\mathrm{N}$ stretching of primary amide \\
1390 & Aldehydes \\
1150 & Ketones \\
$1030,950,850,700$ & $-\mathrm{P}-\mathrm{O},-\mathrm{S}-\mathrm{O}$, and aromatic-CH stretching \\
\hline
\end{tabular}


phenol on the nanoparticles from Spirulina sp. LEB 18 after the biosorption process.

\section{Biosorption kinetic curves}

The kinetic curves of phenol biosorption onto nanoparticles from Spirulina sp. LEB 18 were obtained at initial concentrations of $50,150,250$ and $450 \mathrm{mg} \mathrm{L}^{-1}$ and stirring rates of 50, 200 and $400 \mathrm{rpm}$.

Fig. 2 shows the initial concentration effect on the biosorption kinetic curves. For all initial phenol concentrations, typical kinetic curves were found. An initial curved step was verified until 35$40 \mathrm{~min}$, after the biosorption rate decreased considerably. It was found that an increase in the initial phenol concentration, from 50 to $450 \mathrm{mg} \mathrm{L}^{-1}$ caused an increase of about five fold in the biosorption capacity. This can be attributed to the high concentration gradient between the solution and the nanoparticles surface, which occurs at higher phenol concentration. Furthermore, at higher initial concentration, more biosorption accessible sites on the nanoparticles surface can be occupied by the phenol molecules. Similar trend was observed by Nadavala et al. [7] in the phenol biosorption onto chitosan calcium alginate blended beads.

The stirring rate effect on the biosorption kinetic curves is shown in Fig. 3. It was verified in Fig. 3, that the biosorption rate was faster when stirring rates of 200 or 400 rpm were used. In addition, it was found that the biosorption capacity was favored at $400 \mathrm{rpm}$ during the experiment time. This behavior is due to the increase in the energy dissipation and turbulence in the mixing zone at higher stirring rates [27]. In this way, the external mass transfer resistance is decreased, facilitating the movement of phenol molecules in solution. Dotto et al. [20], studying the biosorption of synthetic dyes onto Spirulina platensis nanoparticles obtained similar results.

\section{Kinetic models evaluation}

The models of pseudo-first order, pseudo-second order, Elovich, Bangham and general order were fitted to the experimental data in order to obtain information about the biosorption process, and the results are shown in Table 2.

Based on the higher values of determination coefficient $\left(R^{2}>0.98\right)$, adjusted determination coefficient $\left(R^{2} a d j>0.98\right)$ and the lower values of average relative error ( $A R E<8.0 \%$ ), sum of squared errors $(S S E<85)$ and Akaike information criterion

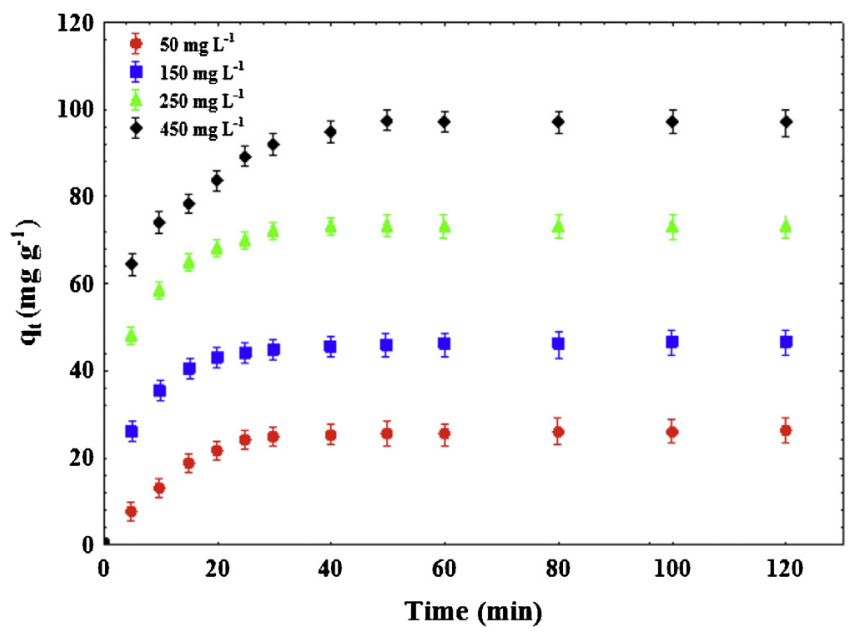

Fig. 2. Kinetic curves for the phenol biosorption by nanoparticles from Spirulina sp. LEB 18 under different initial concentrations ( $50 \mathrm{mg} \mathrm{L}^{-1}$; $150 \mathrm{mg} \mathrm{L}^{-1}$; $\left.250 \mathrm{mg} \mathrm{L}^{-1} ; \quad 450 \mathrm{mg} \mathrm{L}^{-1}\right)(400 \mathrm{rpm})$.

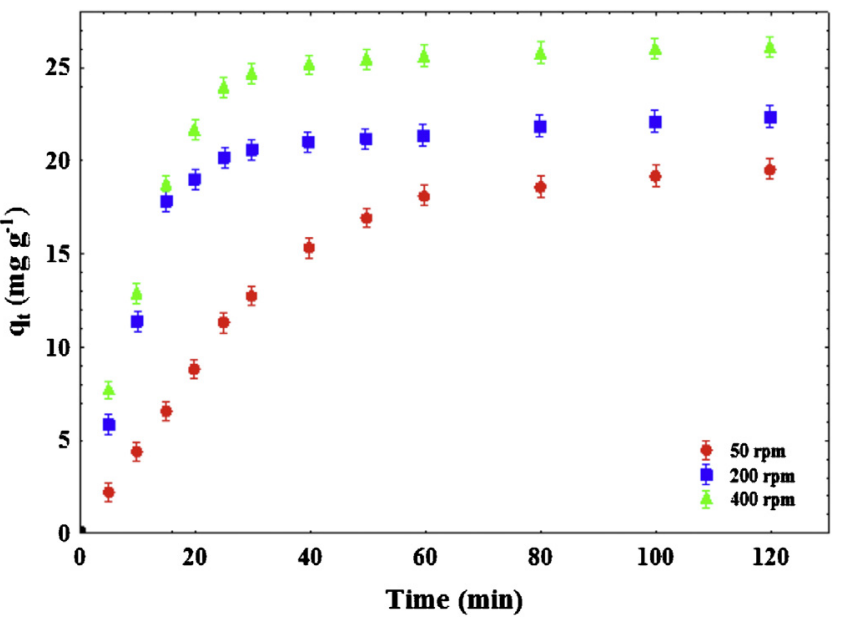

Fig. 3. Kinetic curves for the phenol biosorption by nanoparticles from Spirulina sp. LEB 18 under different stirring rates ( $50 \mathrm{rpm}$; $200 \mathrm{rpm}$; $400 \mathrm{rpm}$ ) (50 $\mathrm{mg} \mathrm{L}^{-1}$ ).

$(A I C<30)$, it can be affirmed that the kinetic models of pseudosecond order and general order were the more adequate to represent the phenol biosorption onto nanoparticles from Spirulina sp. LEB 18.

In relation to the pseudo-second order model, it was found that the increases in initial phenol concentration and stirring rate caused an increase in the $q_{2}$ values (Table 2). This indicates that the phenol biosorption capacity was favored at $450 \mathrm{mg} \mathrm{L}^{-1}$ and $400 \mathrm{rpm}$. It was also observed in Table 2 that the pseudo-second order rate constant $\left(k_{2}\right)$ was higher at $450 \mathrm{mg} \mathrm{L}^{-1}$ and $400 \mathrm{rpm}$, indicating that the biosorption was faster in these conditions. The pseudo-second order model was also adequate to represent the phenol biosorption on P. chrysosporium [6].

The general order kinetic equation presented different orders $(n)$ as a function of the initial phenol concentration and stirring rate (Table 2). So, it is difficult to compare the kinetic parameters of the model. It is useful to use the initial sorption rate $h_{0}\left(\mathrm{mg} \mathrm{g}^{-1} \mathrm{~min}^{-1}\right)$ as demonstrated in Eq. (13) [22,26,33]:

$h_{0}=k_{n}\left(q_{n}\right)^{n}$

Table 2 shows that the increases in initial phenol concentration and stirring rate caused an increase in the initial sorption rate $\left(h_{0}\right)$, indicating that, in the initial stages, the biosorption capacity and the biosorption rate were higher at $450 \mathrm{mg} \mathrm{L}^{-1}$ and $400 \mathrm{rpm}$. This trend corroborates the dependence of $k_{2}$ and $q_{2}$ (pseudo-second order model) with the initial phenol concentration and stirring rate, and also is coherent with the experimental data. Cardoso et al. [22], in the adsorption of reactive red 120 onto S. platensis, showed that the general order model was the more adequate. They verified the same dependence of $h_{0}$ with the initial concentration.

It was also verified in Table 2 that the Bangham model was inadequate to represent the experimental kinetic data. This shows that the phenol biosorption onto nanoparticles from Spirulina sp. LEB 18 was not controlled by pore diffusion [35,39].

The maximum biosorption capacity obtained in this work was about $101 \mathrm{mg} \mathrm{g}^{-1}$ (Table 2). This value was compared with the literature and the results are presented in Table 3 . The results presented in Table 3 show that the biosorption capacity of the nanoparticles from Spirulina sp. LEB 18 is comparable with other sorbents. Furthermore, the nanoparticles from Spirulina sp. LEB 18 are eco-friendly, relatively cheap, renewable and available in large quantities [13-25]. In this way, it can be affirmed that the nanoparticles from Spirulina sp. LEB 18 are a promising biosorbent to remove phenol from aqueous solutions. 
Table 2

Kinetic parameters for the phenol biosorption by nanoparticles from Spirulina sp. LEB 18.

\begin{tabular}{|c|c|c|c|c|c|c|c|c|c|c|c|c|}
\hline \multirow{2}{*}{$\begin{array}{l}\text { Stirring rate }(\mathrm{rpm}) \\
\text { Initial concentration }\left(\mathrm{mg} \mathrm{L}^{-1}\right)\end{array}$} & \multicolumn{4}{|l|}{50} & \multicolumn{4}{|l|}{200} & \multicolumn{4}{|l|}{400} \\
\hline & 50 & 150 & 250 & 450 & 50 & 150 & 250 & 450 & 50 & 150 & 250 & 450 \\
\hline \multicolumn{13}{|l|}{ Pseudo-first order model } \\
\hline$q_{1}\left(\mathrm{mgg}^{-1}\right)$ & $20.5 \pm 2.8$ & $42.0 \pm 1.5$ & $56.7 \pm 5.7$ & $85.4 \pm 6.2$ & $22.0 \pm 2.5$ & $43.9 \pm 2.3$ & $65.6 \pm 3.0$ & $91.2 \pm 6.5$ & $26.2 \pm 1.0$ & $45.8 \pm 1.0$ & $72.1 \pm 1.4$ & $93.9 \pm 3.4$ \\
\hline$k_{1}\left(\min ^{-1}\right)$ & 0.031 & 0.106 & 0.194 & 0.211 & 0.086 & 0.110 & 0.167 & 0.209 & 0.080 & 0.152 & 0.178 & 0.182 \\
\hline$R^{2}$ & 0.9894 & 0.9975 & 0.9613 & 0.9548 & 0.9817 & 0.9847 & 0.9732 & 0.9477 & 0.9920 & 0.9976 & 0.9904 & 0.9632 \\
\hline$R_{a d j}^{2}$ & 0.9884 & 0.9973 & 0.9578 & 0.9507 & 0.9800 & 0.9833 & 0.9708 & 0.9429 & 0.9913 & 0.9974 & 0.9895 & 0.9598 \\
\hline $\operatorname{ARE}(\%)$ & 8.48 & 1.48 & 4.81 & 5.41 & 5.72 & 3.48 & 4.18 & 6.11 & 3.44 & 1.39 & 2.47 & 4.89 \\
\hline SSE & 5.95 & 4.71 & 132.11 & 320.62 & 11.01 & 30.47 & 110.69 & 428.26 & 6.72 & 5.05 & 47.64 & 315.34 \\
\hline AIC & -4.95 & -7.98 & 35.34 & 46.87 & 3.04 & 16.28 & 33.04 & 50.63 & -3.38 & -7.09 & 22.08 & 46.65 \\
\hline \multicolumn{13}{|l|}{ Pseudo-second order model } \\
\hline$q_{2}\left(\mathrm{mgg}^{-1}\right)$ & $27.2 \pm 1.2$ & $46.6 \pm 1.3$ & $63.6 \pm 1.5$ & $91.9 \pm 1.5$ & $25.0 \pm 1.5$ & $48.4 \pm 1.2$ & $70.1 \pm 0.7$ & $98.8 \pm 1.7$ & $29.8 \pm 1.8$ & $49.4 \pm 1.4$ & $76.7 \pm 1.3$ & $100.9 \pm 1.6$ \\
\hline$k_{2} \times 10^{3}\left(\mathrm{~g} \mathrm{mg}^{-1} \mathrm{~min}^{-1}\right)$ & 0.986 & 3.048 & 3.316 & 6.473 & 2.468 & 3.450 & 3.640 & 6.797 & 3.500 & 4.260 & 4.580 & 6.964 \\
\hline 然 & 0.9971 & 0.9961 & 0.9928 & 0.9921 & 0.9928 & 0.9969 & 0.9981 & 0.9899 & 0.9839 & 0.9926 & 0.9966 & 0.9930 \\
\hline$R_{a d j}^{2}$ & 0.9951 & 0.9948 & 0.9921 & 0.9914 & 0.9920 & 0.9966 & 0.9979 & 0.9889 & 0.9826 & 0.9919 & 0.9963 & 0.9924 \\
\hline ARE (\%) & 4.69 & 3.59 & 1.91 & 2.22 & 4.60 & 1.38 & 1.12 & 2.59 & 7.69 & 2.28 & 1.43 & 2.01 \\
\hline SSE & 12.84 & 26.54 & 24.58 & 56.43 & 28.40 & 6.14 & 7.89 & 82.75 & 30.17 & 15.35 & 17.04 & 59.92 \\
\hline AIC & 5.04 & 14.48 & 13.48 & 24.29 & 15.36 & -4.55 & -1.28 & 29.26 & 16.15 & 7.36 & 8.72 & 25.06 \\
\hline \multicolumn{13}{|l|}{ Elovich model } \\
\hline$a\left(\mathrm{~g} \mathrm{mg}^{-1}\right)$ & 0.124 & 0.139 & 0.165 & 0.100 & 0.217 & 0.139 & 0.147 & 0.086 & 0.179 & 0.177 & 0.138 & 0.091 \\
\hline$b\left(\mathrm{mg} \mathrm{g}^{-1} \mathrm{~min}^{-1}\right)$ & 0.89 & 38.79 & 2415.51 & 1051.07 & 8.09 & 50.69 & 2138.59 & 598.97 & 8.61 & 318.49 & 2852.36 & 1082.30 \\
\hline$R^{2}$ & 0.9613 & 0.9419 & 0.9928 & 0.9982 & 0.8952 & 0.9740 & 0.9937 & 0.9952 & 0.9096 & 0.9549 & 0.9716 & 0.9851 \\
\hline$R_{a d j}^{2}$ & 0.9578 & 0.9366 & 0.9921 & 0.9980 & 0.8856 & 0.9716 & 0.9931 & 0.9948 & 0.9014 & 0.9508 & 0.9690 & 0.9837 \\
\hline ARE (\%) & 14.76 & 7.61 & 2.08 & 1.00 & 14.22 & 4.74 & 1.91 & 1.58 & 12.29 & 5.64 & 4.28 & 3.06 \\
\hline SSE & 21.73 & 11.32 & 24.61 & 12.36 & 63.08 & 51.87 & 25.89 & 39.02 & 75.55 & 94.18 & 141.61 & 127.25 \\
\hline AIC & 11.88 & 33.12 & 13.49 & 4.55 & 25.73 & 23.19 & 14.16 & 19.49 & 28.08 & 30.94 & 36.24 & 34.85 \\
\hline \multicolumn{13}{|l|}{ Bangham model } \\
\hline$k_{0}\left(\mathrm{Lg}^{-1}\right)$ & 0.051 & 0.307 & 0.416 & 0.295 & 0.252 & 0.331 & 0.459 & 0.299 & 0.069 & 0.465 & 0.517 & 0.324 \\
\hline$\alpha$ & 0.77 & 0.26 & 0.14 & 0.15 & 0.52 & 0.26 & 0.15 & 0.17 & 1.10 & 0.19 & 0.15 & 0.16 \\
\hline$R^{2}$ & 0.9611 & 0.9293 & 0.9913 & 0.9967 & 0.9075 & 0.9698 & 0.9921 & 0.9929 & 0.9891 & 0.9502 & 0.9689 & 0.9816 \\
\hline$R_{a d j}^{2}$ & 0.9576 & 0.9229 & 0.9905 & 0.9964 & 0.8992 & 0.9671 & 0.9914 & 0.9923 & 0.9880 & 0.9457 & 0.9661 & 0.9799 \\
\hline ARE (\%) & 14.35 & 8.47 & 2.31 & 1.41 & 13.27 & 5.41 & 2.14 & 1.98 & 3.15 & 5.93 & 4.46 & 3.44 \\
\hline SSE & 21.87 & 135.48 & 29.54 & 23.58 & 55.71 & 66.33 & 32.63 & 57.41 & 9.17 & 103.93 & 154.68 & 157.03 \\
\hline AIC & 11.96 & 35.67 & 15.87 & 12.94 & 24.12 & 26.39 & 17.16 & 24.51 & 0.66 & 32.22 & 37.39 & 37.59 \\
\hline \multicolumn{13}{|l|}{ General order model } \\
\hline$q_{n}\left(\mathrm{mgg}^{-1}\right)$ & $19.4 \pm 1.0$ & $42.3 \pm 0.5$ & $66.7 \pm 0.7$ & $92.9 \pm 0.8$ & $21.5 \pm 1.2$ & $47.1 \pm 0.5$ & $72.4 \pm 0.2$ & $99.4 \pm 0.9$ & $25.9 \pm 1.1$ & $46.4 \pm 1.1$ & $74.2 \pm 0.7$ & $101.8 \pm 1.0$ \\
\hline$k_{n}\left(\mathrm{~min}^{-1}\left(\mathrm{~g} \mathrm{mg}^{-1}\right)^{\mathrm{n}-1}\right)$ & 0.0680 & 0.0809 & 0.0006 & 0.0019 & 0.1148 & 0.0082 & 0.0010 & 0.0019 & 0.1092 & 0.0663 & 0.0255 & 0.0019 \\
\hline$n$ & 0.71 & 1.08 & 2.58 & 2.15 & 0.90 & 1.76 & 2.38 & 2.12 & 0.89 & 1.26 & 1.66 & 2.11 \\
\hline$h_{0}\left(\mathrm{mgg}^{-1} \min ^{-1}\right)$ & 0.56 & 4.62 & 30.51 & 32.36 & 1.82 & 7.22 & 31.66 & 32.60 & 1.97 & 8.34 & 32.46 & 32.74 \\
\hline$R^{2}$ & 0.9949 & 0.9977 & 0.9957 & 0.9937 & 0.9929 & 0.9973 & 0.9995 & 0.9911 & 0.9946 & 0.9997 & 0.9985 & 0.9935 \\
\hline$R_{a d j}^{2}$ & 0.9939 & 0.9972 & 0.9948 & 0.9924 & 0.9925 & 0.9968 & 0.9994 & 0.9893 & 0.9935 & 0.9996 & 0.9982 & 0.9922 \\
\hline ARE (\%) & 5.87 & 1.31 & 1.56 & 1.99 & 5.51 & 1.41 & 0.56 & 2.47 & 2.78 & 0.34 & 0.97 & 1.99 \\
\hline SSE & 2.83 & 4.26 & 14.39 & 44.81 & 10.27 & 5.39 & 1.99 & 73.51 & 4.51 & 0.42 & 7.64 & 55.66 \\
\hline$A I C$ & -11.14 & -5.85 & 10.16 & 24.74 & 5.59 & -2.76 & -15.71 & 29.18 & -5.11 & -35.96 & 1.75 & 27.56 \\
\hline
\end{tabular}


Table 3

Comparison of nanoparticles from Spirulina sp. LEB 18 with other sorbents for the removal of phenol.

\begin{tabular}{|c|c|c|c|c|c|c|}
\hline Sorbent material & $\begin{array}{l}\text { Sorbent dosage } \\
\left(\mathrm{g} \mathrm{L}^{-1}\right)\end{array}$ & $\begin{array}{l}\text { Phenol concentration } \\
\left(\mathrm{mg} \mathrm{L}^{-1}\right)\end{array}$ & $\mathrm{pH}$ & $\begin{array}{l}\text { Temperature } \\
(\mathrm{K})\end{array}$ & $\begin{array}{l}\text { Biosorption capacity } \\
\left(\mathrm{mg} \mathrm{g}^{-1}\right)\end{array}$ & Reference \\
\hline Nanoparticles from Spirulina sp. LEB 18 & 1.85 & 450 & 6.0 & 298 & 101 & This work \\
\hline Phanerochaete chrysosporium & 0.3 & $10-100$ & 6.0 & 295.5 & 13.5 & [6] \\
\hline Chitosan & 4.0 & 300 & 7.0 & 298 & 116.3 & [7] \\
\hline Fungal mycelia & 5.0 & $10-70$ & - & 298 & 5.0 & [10] \\
\hline Funalia trogii & 0.25 & $30-600$ & 8.0 & 298 & 147.0 & [12] \\
\hline Corn grain-based activated carbons & 0.25 & 100 & 3.0 & 293 & 256 & {$[40]$} \\
\hline Charred sawdust of sheesham & 1.0 & $10-1000$ & 6.0 & 318 & 344.8 & [41] \\
\hline Exfoliated graphitic nanoplatelets & 0.4 & 125 & 6.0 & 298 & 119.2 & [42] \\
\hline Lignite activated carbon & 0.5 & $50-500$ & 4.0 & 298 & 42.3 & [43] \\
\hline Organomontmorillonite & 10 & $50-5000$ & - & 298 & 526.3 & [44] \\
\hline
\end{tabular}

Table 4

Weber-Morris parameters for the phenol biosorption by nanoparticles from Spirulina sp. LEB 18.

\begin{tabular}{|c|c|c|c|c|c|c|c|c|c|c|c|c|}
\hline \multirow{2}{*}{$\begin{array}{l}\text { Stirring rate }(\mathrm{rpm}) \\
\text { Initial concentration }\left(\mathrm{mg} \mathrm{L}^{-1}\right)\end{array}$} & \multicolumn{4}{|l|}{50} & \multicolumn{4}{|l|}{200} & \multicolumn{4}{|l|}{400} \\
\hline & 50 & 150 & 250 & 450 & 50 & 150 & 250 & 450 & 50 & 150 & 250 & 450 \\
\hline \multicolumn{13}{|l|}{ First linear portion } \\
\hline$k_{d 1}\left(\mathrm{mg} \mathrm{g}^{-1} \min ^{-1 / 2}\right)$ & 3.24 & 4.54 & 6.94 & 6.99 & 6.28 & 6.68 & 7.06 & 8.22 & 6.43 & 7.75 & 7.97 & 8.59 \\
\hline$C_{1}\left(\mathrm{mg} \mathrm{g}^{-1}\right)$ & -5.5 & 4.5 & 34.4 & 45.9 & -8.1 & 7.8 & 31.5 & 44.8 & -6.9 & 9.5 & 31.9 & 45.6 \\
\hline$R^{2}$ & 0.9918 & 0.9755 & 0.9973 & 0.9909 & 0.9701 & 0.9807 & 0.9939 & 0.9754 & 0.9921 & 0.9799 & 0.9863 & 0.9923 \\
\hline ARE (\%) & 6.49 & 5.41 & 0.39 & 0.88 & 5.15 & 1.91 & 0.76 & 2.67 & 0.21 & 1.98 & 3.41 & 0.12 \\
\hline \multicolumn{13}{|l|}{ Second linear portion } \\
\hline$k_{d 2}\left(\mathrm{mg} \mathrm{g}^{-1} \min ^{-1 / 2}\right)$ & 0.44 & 0.48 & 0.63 & 2.05 & 0.34 & 0.88 & 1.02 & 4.53 & 0.19 & 0.68 & 0.73 & 3.42 \\
\hline$C_{2}\left(\mathrm{mgg}^{-1}\right)$ & 14.6 & 37.8 & 56.3 & 71.0 & 18.7 & 36.6 & 58.8 & 60.7 & 24.0 & 40.9 & 68.2 & 72.9 \\
\hline$R^{2}$ & 0.9984 & 0.9914 & 0.9792 & 0.9927 & 0.9703 & 0.9777 & 0.9807 & 0.9779 & 0.9835 & 0.9856 & 0.9798 & 0.9986 \\
\hline$A R E(\%)$ & 0.09 & 0.16 & 0.17 & 0.34 & 0.46 & 5.23 & 4.56 & 5.32 & 3.76 & 5.41 & 4.81 & 0.16 \\
\hline
\end{tabular}

\section{Weber-Morris analysis}

In this work, the Weber-Morris analysis was employed to identify the mass transfer steps that occur in the biosorption process. According to Weber and Morris [36], the plot $q_{t}$ versus $t^{1 / 2}$ shows multi linearity, and each linear portion represents a distinct mass transfer mechanism. The first linear portion can be attributed to the external mass transfer mechanism. The second portion is relative to the intraparticle diffusion, and the third is the final equilibrium. Furthermore, if the regression passes through the origin, then the rate limiting process is only due to the intraparticle diffusion. Otherwise, the intraparticle diffusion is not the only ratecontrolling step and some degrees of boundary layer diffusion also control the biosorption [20,22,27,36,37,39]. Figs. 4 and 5 show,

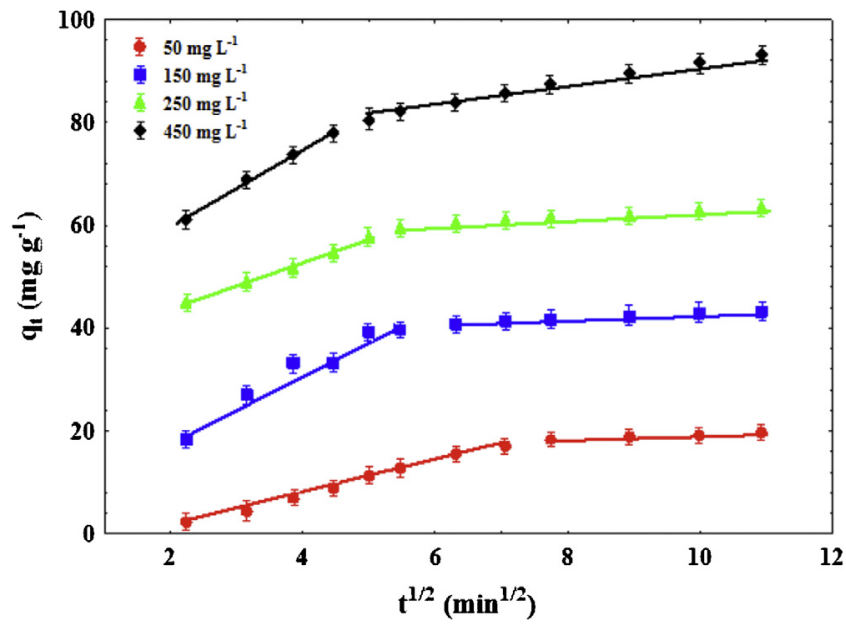

Fig. 4. Weber-Morris plots for the phenol biosorption by nanoparticles from Spirulina sp. LEB 18 under different initial concentrations (o $50 \mathrm{mg} \mathrm{L}^{-1}$; $\left.150 \mathrm{mg} \mathrm{L}^{-1} ; \quad 250 \mathrm{mg} \mathrm{L}^{-1} ; \diamond 450 \mathrm{mg} \mathrm{L}^{-1}\right)(50 \mathrm{rpm})$. respectively, the Weber-Morris plots for the biosorption of phenol by nanoparticles from Spirulina sp. LEB 18 under different initial concentrations and stirring rates. The values of $k_{d}$ and $C$ for each linear portion are shown in Table 4.

Figs. 4 and 5 show two distinct linear portions for the phenol biosorption by nanoparticles from Spirulina sp. LEB 18 . The first and second linear portions can be attributed to the external mass transfer and intraparticle diffusion mechanisms, respectively [20,22]. Furthermore, it was found that the regression not passes through the origin (Figs. 4, 5 and Table 4), showing that the intraparticle diffusion is not the only rate-controlling step in the biosorption process [40]. So, it can be inferred that external mass transfer and intraparticle diffusion occurred simultaneously during the phenol biosorption onto Spirulina sp. nanoparticles.

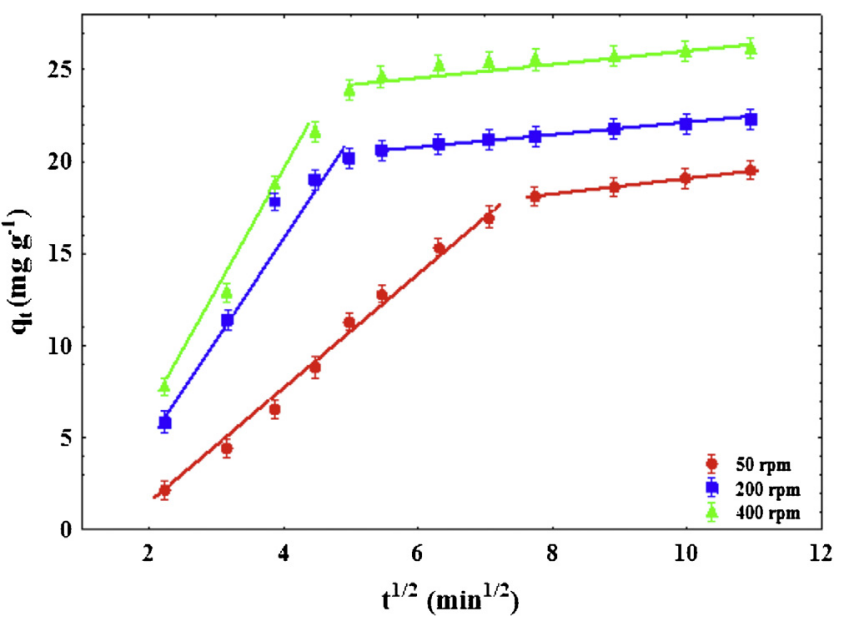

Fig. 5. Weber-Morris plots for the phenol biosorption by nanoparticles from Spirulina sp. LEB 18 under different stirring rates $(50 \mathrm{rpm}$; $200 \mathrm{rpm}$; $400 \mathrm{rpm})\left(50 \mathrm{mg} \mathrm{L}^{-1}\right)$. 
The increases in initial phenol concentration and stirring rate caused an increase in the $k_{d 1}$ values (Table 4). This shows that the external mass transfer was facilitated at higher values of initial phenol concentration and stirring rate. The $k_{d 2}$ values (Table 4) increased with the initial phenol concentration, indicating that the intraparticle diffusion was favored at high initial concentrations. Similar trends for $k_{d 1}$ and $k_{d 2}$ were found by Park et al. [40] in the adsorption of phenol onto activated carbon.

\section{Conclusion}

In this research, the biosorption kinetics of phenol onto nanoparticles from Spirulina sp. LEB 18 was studied under different conditions of initial phenol concentration and stirring rate. The nanoparticles from Spirulina sp. LEB 18 possess potential characteristics to remove phenol from aqueous solutions. The kinetic curves showed that the phenol biosorption was favored at higher values of initial concentration and stirring rate. The pseudo-second order and general order models were adequate to represent the biosorption kinetics, being the maximum biosorption capacity around $101 \mathrm{mg} \mathrm{g}^{-1}$. The Weber-Morris analysis demonstrated that external mass transfer and intraparticle diffusion occurred simultaneously during the phenol biosorption onto nanoparticles from Spirulina sp. LEB 18.

\section{Acknowledgments}

The authors would like to thank CAPES (Coordination for the Improvement of Higher Education Personnel), CNPq (National Council for Scientific and Technological Development) and REDE NANOFOTOBIOTEC for the financial support.

\section{References}

[1] G. Busca, S. Berardinelli, C. Resini, L. Arrighi, Technologies for the removal of phenol from fluid streams: a short review of recent developments, J. Hazard. Mater. 160 (2008) 265-288.

[2] USEPA, Technical Support Document for Water Quality Based Toxics Control, EPA/440/ 485032, United States Environmental Protection Agency, Washington, DC, USA, 1.985

[3] S.H. Lin, R.S. Juang, Adsorption of phenol and its derivatives from water using synthetic resins and low-cost natural adsorbents: a review, J. Environ. Manage. 90 (2009) 1336-1349.

[4] M. Kurian, R. Babu, Iron aluminium mixed pillared montmorillonite and the rare earth exchanged analogues as efficient catalysts for phenol oxidation, J. Environ. Chem. Eng. 1 (2013) 86-91.

[5] S.N. Hussain, E.P.L. Roberts, H.M.A. Asghar, A.K. Campen, N.W. Brown, Oxidation of phenol and the adsorption of breakdown products using a graphite adsorbent with electrochemical regeneration, Electrochim. Acta 92 (2013) 20-30.

[6] V. Farkas, A. Felinger, A. Hegedusovac, I. Dekanyde, T. Pernyeszi, Comparative study of the kinetics and equilibrium of phenol biosorption on immobilized white-rot fungus Phanerochaete chrysosporium from aqueous solution, Colloids Surf., B 103 (2013) 381-390.

[7] S.K. Nadavala, K. Swayampakula, V.M. Boddu, K. Abburi, Biosorption of phenol and o-chlorophenol from aqueous solutions on to chitosan calcium alginate blended beads, J. Hazard. Mater. 162 (2009) 482-489.

[8] Z. Aksu, Application of biosorption for the removal of organic pollutants: a review, Proc. Biochem. 40 (2005) 997-1026.

[9] Y. Liu, Y.J. Liu, Biosorption isotherms, kinetics and thermodynamics, Sep. Purif. Technol. 61 (2008) 229-242.

[10] J. Wu, H.Q. Yu, Biosorption of phenol and chlorophenols from aqueous solutions by fungal mycelia, Proc. Biochem. 41 (2006) 44-49.

[11] A.E. Navarro, R.F. Portales, M.R. Sun-Kou, B.P. Llanos, Effect of pH on phenol biosorption by marine seaweeds, J. Hazard. Mater. 156 (2008) 405-411.

[12] G. Bayramoglu, I. Gursel, Y. Tunali, M.Y. Arica, Biosorption of phenol and 2chlorophenol by Funalia trogii pellets, Bioresour. Technol. 100 (2009) 2685-2691.

[13] A. Vonshak, Spirulina platensis (Arthrospira) physiology, in: Cell-Biology and Biotechnology, Taylor \& Francis, London, 1997.

[14] A. Çelekli, M. Yavuzatmac, H. Bozkurt, An eco-friendly process: predictive modeling of copper adsorption from aqueous solution on Spirulina platensis, J. Hazard Mater. 173 (2010) 123-129.
[15] G.L. Dotto, T.R.S. Cadaval Jr., L.A.A. Pinto, Use of Spirulina platensis micro and nanoparticles for the removal synthetic dyes from aqueous solutions by biosorption, Proc. Biochem. 47 (2012) 1335-1343.

[16] J.A.V. Costa, M.G. Morais, The role of biochemical engineering in the production of biofuels from microalgae, Bioresour. Technol. 102 (2011) 2-9.

[17] J.A. Borges, G.M. Rosa, L.H.R. Meza, A.A. Henrard, M.R.A.Z. Souza, J.A.V. Costa, Spirulina sp. LEB-18 culture using effluent from the anaerobic digestion, Braz. J. Chem. Eng. 30 (2013) 277-287.

[18] G.L. Dotto, V.M. Esquerdo, M.L.G. Vieira, L.A.A. Pinto, Optimization and kinetic analysis of food dyes biosorption by Spirulina platensis, Colloids Surf., B 91 (2012) 234-241.

[19] G.L. Dotto, E.C. Lima, L.A.A. Pinto, Biosorption of food dyes onto Spirulina platensis nanoparticles: equilibrium isotherm and thermodynamic analysis, Bioresour. Technol. 103 (2012) 123-130.

[20] G.L. Dotto, L.A.A. Pinto, Analysis of mass transfer kinetics in the biosorption of synthetic dyes onto Spirulina platensis nanoparticles, Biochem. Eng. J. 68 (2012) 85-90.

[21] G.L. Dotto, M.L.G. Vieira, V.M. Esquerdo, L.A.A. Pinto, Equilibrium and thermodynamics of azo dyes biosorption onto Spirulina platensis, Braz. J. Chem. Eng. 30 (2013) 13-21.

[22] N.F. Cardoso, E.C. Lima, B. Royer, M.V. Bach, G.L. Dotto, L.A.A. Pinto, T. Calvete, Comparison of Spirulina platensis microalgae and commercial activated carbon as adsorbents for the removal of reactive red 120 dye from aqueous effluents, J. Hazard. Mater. 241-242 (2012) 146-153.

[23] G.L. Dotto, T.R.S. Cadaval Jr., L.A.A. Pinto, Preparation of bionanoparticles derived from Spirulina platensis and its application for $\mathrm{Cr}(\mathrm{VI})$ removal from aqueous solutions, J. Ind. Eng. Chem. 18 (2012) 1925-1930.

[24] L. Fang, C. Zhou, P. Cai, W. Chen, X. Rong, K. Dai, W. Liang, J. Gu, Q. Huang, Binding characteristics of copper and cadmium by cyanobacterium Spirulina platensis, J. Hazard. Mater. 190 (2011) 810-815.

[25] M.S. Rodrigues, L.S. Ferreira, J.C. Monteiro de Carvalho, A. Lodi, E. Finocchio, A. Converti, Metal biosorption onto dry biomass of Arthrospira (Spirulina) platensis and Chlorella vulgaris: multi-metal systems, J. Hazard. Mater. 217/218 (2012) 246-255.

[26] H. Qiu, L.L. Pan, Q.J. Zhang, W. Zhang, Q. Zhang, Critical review in adsorption kinetic models, J. Zhejiang Univ. Sci. A 10 (2009) 716-724.

[27] G.L. Dotto, L.A.A. Pinto, Adsorption of food dyes acid blue 9 and food yellow 3 onto chitosan: stirring rate effect in kinetics and mechanism, J. Hazard. Mater. 187 (2011) 164-170.

[28] J.A.V. Costa, L.M. Colla, P.F.D. Filho, Improving Spirulina platensis biomass yield using a fed-batch process, Bioresour. Technol. 92 (2004) 237-241.

[29] E.G. Oliveira, G.S. Rosa, M.A. Moraes, L.A.A. Pinto, Characterization of thin layer drying of Spirulina platensis utilizing perpendicular air flow, Bioresour. Technol. 100 (2009) 1297-1303.

[30] J. Bruce, R. Pecora, Dynamic Light Scattering: With Applications to Chemistry, Biology and Physics, Dover Publications, New York, 2000.

[31] R.M. Silverstein, F.X. Webster, D.J. Kiemle, Spectrometric Identification of Organic Compounds, John Wiley \& Sons, New York, 2007.

[32] S. Lagergren, About the theory of so-called adsorption of soluble substances, K. Sven. Vetenskapsakad. Handl. 24 (1898) 1-39.

[33] Y.S. Ho, G. McKay, A comparison of chemisorption kinetic models applied to pollutant removal on various sorbents, Process Saf. Environ. Prot. 76 (1998) 332340.

[34] F.C. Wu, R.L. Tseng, R.S. Juang, Characteristics of Elovich equation used for the analysis of adsorption kinetics in dye chitosan systems, Chem. Eng. J. 150 (2009) 366-373.

[35] D.H. Bangham, F.P. Burt, The behavior of gases in contact with glass surfaces, Proc. R. Soc. London, Ser. A: Math. Phys. Character 105 (1924) 481-488.

[36] W.J. Weber, J.C. Morris, Kinetics of adsorption of carbon from solutions, J. Sanit. Eng. Div., Am. Soc. Civ. Eng. 89 (1963) 31-63.

[37] M.I. El-Khaiary, G.F. Malash, Common data analysis errors in batch adsorption studies, Hydrometallurgy 105 (2011) 314-320.

[38] H. Bozdogan, Model selection and Akaike's information criterion (AIC): the general theory and its analytical extensions, Psychometrika 52 (1987) 345-370.

[39] G.L. Dotto, M.L.G. Vieira, L.A.A. Pinto, Kinetics and mechanism of tartrazine adsorption onto chitin and chitosan, Ind. Eng. Chem. Res. 51 (2012) 6862-6868.

[40] K.H. Park, M.S. Balathanigaimani, W.G. Shim, J.W. Lee, H. Moon, Adsorption characteristics of phenol on novel corn grain-based activated carbons, Microporous Mesoporous Mater. 127 (2010) 1-8

[41] S. Mubarik, A. Saeed, Z Mehmood, M. Iqbal, Phenol adsorption by charred sawdust of sheesham (Indian rosewood; Dalbergia sissoo) from single, binary and ternary contaminated solutions, J. Taiwan Inst. Chem. Eng. 43 (2012) 926933.

[42] A.C. Ion, A. Alpatova, I. Ion, A. Culetu, Study on phenol adsorption from aqueous solutions on exfoliated graphitic nanoplatelets, Mater. Sci. Eng., B 176 (2011) 588-595.

[43] G. Lü, J. Hao, L. Liu, H. Ma, O. Fang, L. Wu, M. Wei, Y. Zhang, The adsorption of phenol by lignite activated carbon, Chin. J. Chem. Eng. 19 (2011) 380-385.

[44] J. Su, H. Lin, Q.P. Wang, Z.M. Xie, Z.L. Chen, Adsorption of phenol from aqueous solutions by organomontmorillonite, Desalination 269 (2011) 163-169. 